\title{
Health services in central and eastern Europe: past problems and future prospects
}

\author{
Martin McKee
}

The past and the present

As the peoples of central and eastern Europe ${ }^{a}$ move into the 1990s they are abandoning some of their initial euphoria and coming to terms with the enormity of the task confronting them. During 45 years of authoritarian rule the perceived interests of the state took priority over those of the individual. Uneconomical and environmentally damaging heavy industry swallowed up resources that could otherwise have been used for health care. Throughout this time the governments were able to present their societies as utopian paradises, in which health for all was virtually achieved and everyone was equal. In 1988 the Czech Ministry of Health stated that "there are no principal differences in the level of health status among population categories" (Janeckova $\mathrm{H}$, personal communication). On the contrary, these governments have left a legacy of deteriorating health, ${ }^{1}$ geographical and social inequality, ${ }^{23}$ industrial decay, environmental damage, ${ }^{4}$ and a deep distrust of central planning and paternalism.

Health care is only one of many problems which the new governments face. In the immediate future they must work to strengthen democracy and the political process, restructure industry, and develop the basic expertise required to function in a market economy. And they must do this at a time when their economic base is weakened further by the collapse of the Comecon trading system and a reduced supply of low cost oil from the Soviet Union.

With all of these problems, it is hardly surprising that health care reform has not been at the top of their agendas. Nonetheless there is a deep seated discontent with the existing systems and widespread recognition that they must change.

The problems which the health services face are enormous. The health status of the people of central and eastern Europe is not only lower than in western Europe, but in some respects it is steadily declining. In most of these countries life expectancy at one year is between four and six years shorter than in the United Kingdom (table I). Almost uniquely in the modern world, male life expectancy has actually fallen in the past decade.

Consumption of alcohol and cigarettes is much higher than in western Europe (table II). This is related to low prices and the lack of alternative

${ }^{\mathrm{a}}$ For the purposes of this review I shall exclude the Soviet Union and Albania. leisure pursuits. The official figures for alcohol consumption are often an underestimate because of illicit production. Cigarettes have much higher tar levels than in western Europe.

The opening of borders, accompanied by rapid social change and a dramatic increase in organised crime, is leading to an upsurge in drug abuse. This is contributing to the rising incidence of HIV infection. ${ }^{5}$

There is a widespread lack of birth control facilities. In most countries abortion has been used as a substitute, giving rise to abortion rates which are much higher than in western Europe (table III). In Romania birth control was prohibited as part of a strategy to increase the population and the consequences of this policy are now notorious. In some countries, such as Poland ${ }^{6}$ and the Slovak Republic, there is also considerable opposition to birth control on religious grounds.

Large parts of central and eastern Europe are environmental disaster areas. ${ }^{4}$ The economies are based on heavy industry which is extremely wasteful of energy. Many of the processes are much more polluting than their equivalents in the West, and there is widespread heavy metal poisoning of the soil. Much of the energy used is produced from low quality coal or lignite, and there is virtually no desulphurisation in power stations. In the heavily industrialised area of Katowice in southern Poland, $20 \%$ of agricultural land is unsuitable for cultivation and half of the forests have been damaged. ${ }^{3}$

Industry is not the only source of pollution. Most sewerage is discharged untreated into rivers. Almost $40 \%$ of Polish rivers are classified as excessively polluted. ${ }^{3}$ While the effects on health are uncertain, the areas with the highest levels of pollution also have the highest premature and infant mortality rates.

The health services, like other government organisations, are centrally planned and based on the Soviet model. Financing is from central government revenues, and although there are some small copayments from which most of the population are exempt, most services are theoretically free at the point of service. However this tells only part of the story as there is a large black economy, with extensive use of tips and gifts to health care staff, contributing up to $30 \%$ of their total salary.

Despite central control, services are highly fragmented. In general, health services have two
Accepted for publication April 1991 
organisational tiers, with vertical organisational structures and referral mechanisms. The lower level is responsible for all primary and secondary services for a defined population. In most cases people have access only to doctors in their area of residence. In turn, these doctors may only refer to designated hospitals. Patient choice is limited both by shortage of drugs and equipment, and by arbitary regulations. In some countries, rising popular demand for services was met with further regulations aimed at reducing access. ${ }^{7}$ There is no means of complaining about inadequate services, and health care has been presented as a "gift" from the state. ${ }^{7}$

Medical practice is dominated by specialisation, with very few general practitioners. Doctors are concentrated in hospitals and are often underemployed. This situation coexists with a severe shortage of nurses and ancillary staff, which is partly due to the extremely low wages in the health sector and which results in considerable labour substitution by medical and scientific staff. Doctors' wages are also extremely low, but are already increasing dramatically. For example, many Bulgarian doctors were paid less than half the average wage, but widespread strikes following the overthrow of Zhivkov resulted in salary increases of over $100 \%{ }^{8}$ It is probable that a substantial component of any increase in health care spending in these countries will be swallowed up immediately in higher salaries.

Table I Male life expectancy (years) at one year of age and infant mortality (male and female) in selected countries

Table II Cigarette and spirits consumption in selected countries

\begin{tabular}{|c|c|c|c|c|}
\hline & 1976 & 1986 & $\begin{array}{l}\text { Change } \\
1976 \text { to } \\
1986\end{array}$ & $\begin{array}{l}\text { Infant } \\
\text { mortality } \\
\text { rate }\end{array}$ \\
\hline $\begin{array}{l}\text { Bulgaria } \\
\text { Czechoslovakia } \\
\text { DDR } \\
\text { Hungary } \\
\text { Poland } \\
\text { Romania } \\
\text { Yugoslavia }\end{array}$ & $\begin{array}{l}69 \cdot 8 \\
67 \cdot 6 \\
69 \\
67 \cdot 9 \\
67 \cdot 8 \\
68 \cdot 9 \\
69 \cdot 4\end{array}$ & $\begin{array}{l}68 \cdot 8 \\
67 \cdot 4 \\
69 \cdot 3 \\
65 \cdot 7 \\
67 \\
67 \cdot 9 \star \\
69 \cdot 2 \dagger\end{array}$ & $\begin{array}{l}-1 \cdot 0 \\
-0.2 \\
+0.3 \\
-2.2 \\
-0.8 \\
-1.0 \\
-0.2\end{array}$ & $\begin{array}{c}14 \cdot 7 \\
13 \cdot 4 \\
9 \cdot 2 \\
19 \cdot 1 \\
17 \cdot 5 \\
23 \cdot 4^{\star} \\
28 \cdot 3 \dagger\end{array}$ \\
\hline $\begin{array}{l}\text { United Kingdom } \\
\text { Federal Republic } \\
\text { of Germany }\end{array}$ & $69 \cdot 6$ & $71 \cdot 7$ & $+2 \cdot 1$ & 9.5 \\
\hline $\begin{array}{l}\text { of Germany } \\
\star 1984\end{array}$ & 69 & $71 \cdot 6$ & $+2 \cdot 6$ & 8.5 \\
\hline
\end{tabular}

\begin{tabular}{|c|c|c|}
\hline Country & $\begin{array}{l}\text { Litres of spirits/ } \\
\text { person/year }\end{array}$ & $\begin{array}{l}\text { Units of cigarettes/ } \\
\text { person/year }\end{array}$ \\
\hline $\begin{array}{l}\text { Bulgaria } \\
\text { Czechoslovakia } \\
\text { DDR } \\
\text { Hungary } \\
\text { Poland } \\
\text { Romania } \\
\text { Yugoslavia }\end{array}$ & $\begin{array}{l}3 \cdot 4 \\
3 \cdot 4 \\
4 \cdot 7 \\
5 \cdot 3 \\
4 \cdot 7 \\
2 \cdot 0 \\
2 \cdot 0\end{array}$ & $\begin{array}{l}1803 \\
1790 \\
1883 \\
2552 \\
2644 \\
1565 \\
2453\end{array}$ \\
\hline $\begin{array}{l}\text { United Kingdom } \\
\text { Federal Republic } \\
\text { of Germany }\end{array}$ & $\begin{array}{l}1 \cdot 7 \\
2 \cdot 3\end{array}$ & 1691 \\
\hline
\end{tabular}

Source: Health for all database. Copenhagen: World Health Organization, 1989

\begin{tabular}{lc}
\hline Bulgaria & 1009 \\
Czechoslovakia & 563 \\
DDR & unavailable \\
Hungary & 651 \\
Poland & 204 \\
USSR & 1210 \\
& \\
Federal Republic of Germany & 134 \\
Netherlands & 99 \\
\hline Source: Health for all database. Copenhagen: World Health \\
Organization, 1989
\end{tabular}

Organization, 1989
Administrative areas are usually small. The districts in Poland (ZoZs) cater for populations of about 100000 . In Hungary the equivalent units may be responsible for as few as 30000 people. The regional level is usually supposed to provide tertiary care facilities, but it also is relatively small for this function. The average population of the Polish regions (Voivodeships) is 750000 and a typical Hungarian province has a population of 400000.

Within districts, services are often provided separately for different groups. In Hungary there are separate facilities for the general population, for factory workers, and for mothers and children. Services are fragmented further with numerous dispensaries, each treating separate diseases. ${ }^{9}$ There is negligible coordination between neighbouring districts leading both to areas of underprovision and to duplication of services.

Separate health services are also provided for several occupational groups and their families in parallel organisations controlled by the relevant ministries. In Bulgaria privileged groups such as "fighters against fascism and capitalism" were treated in separate facilities with better amenities. $^{8}$ The parallel sectors are often relatively large, accounting for $9^{\circ}{ }_{0}$ of all hospital beds in Poland.

Despite claims for the accessibilty of services, ${ }^{9}$ health care facilities are very unevenly distributed. In Hungary, secondary and tertiary services have traditionally been concentrated in Budapest, and while there has been some redistribution during the postwar years it still contains over twice as many specialists and hospital beds per unit of population as in the rest of the country. ${ }^{2}$ The difference is even more dramatic in certain specialties such as orthopaedics. In some countries the maldistribution reflects the historical pattern, but in others siting of new hospitals is a result of political favouritism. In general, support of heavy industry has concentrated health services in towns and cities, although in Bulgaria, where agriculture was seen as a key part of the economy, specific measures were adopted to maintain rural services. ${ }^{10}$

The health service infrastructure is decaying. Most facilities are grossly inadequate, both in design and in physical condition. Most hospitals have a severe shortage of equipment. These problems are compounded by changes in exchange regulations and currency fluctuations. Poland experienced a fourfold rise in the price of medical equipment in January 1990 following the introduction of a convertible zloty. Hospitals were no longer able to make purchases and the central purchasing authority was left with large quantities in storage. The interest payments on this equipment have absorbed most of the authority's budget. Inadequate facilities are especially common outside cities, and the newly found freedom has facilitated a mass exodus of doctors from the rural areas in Romania for example.

The overthrow of the old regimes has uncovered widespread corruption and extensive abuses of power by those in authority. Foreign travel was limited to those approved by the party, and certain individuals derived disproportionate financial benefits. For example, a senior cardiac 
surgeon received a supplement of DM 20000 $(£ 7404)$ per month in addition to his salary. His unit accounted for $25 \%$ of the entire convertible currency budget of the health ministry. ${ }^{8}$

Some countries have sought to replace many of the former officials, and in some cases put them on trial. ${ }^{11}$ This was easier in Czechoslovakia than in other countries as there was a well established dissident movement including individuals with appropriate experience. In the former DDR there has been a massive influx of West Germans. In other sectors some posts have been filled by exiles who had been living in Western Europe or North America, although this has had a negligible effect on health services so far. Some countries have been either unwilling or unable to replace those in authority, in some cases because the party system completely pervaded all aspects of life.

Each country is faced with a dramatic rise in the cost of pharmaceuticals. This was foreseen in the German Unity Treaty which decreed that West German drugs should be sold in the eastern Lander for $45 \%$ of their cost in the west. This difference was to compensate for the lower wage linked income of the eastern health insurance agencies. ${ }^{12}$ However the pharmaceutical companies, who were required to meet the difference, stopped supplies to the east. The popular outcry against the industry led to a compromise solution whereby the industry will maintain its existing prices but will give a large contribution to defray the deficits of the insurance agencies.

Elsewhere the situation has become critical. The Czech and Slovak health ministries were expected to run out of money by September 1991, and the Polish ministry stopped payments to CEFARM, the state owned supplier, in early 1990. Poland had a large pharmaceutical industry and was almost self sufficient during the 1980 s. The industry survived by supplying the protected internal market. However it must now compete with imports, and the obsolete factories cannot meet Western regulatory standards and thus compete abroad.

Despite the almost uniformly pessimistic picture, is it worth recording that the centrally planned systems have had a few successes, mainly in the field of public health. In the immediate postwar period each was faced with high levels of infectious disease and no primary health care infrastructure. They were then able to mobilise resources for large scale immunisation programmes, but this approach is no substitute for the comprehensive, horizontally integrated primary health care systems which they have failed to develop.

\section{Plans for reform}

Although the reform plans of the countries in the region have many similarities, they also reflect the political history of individual countries. Some features of the plans of each country will now be considered.

\section{POLAND}

The need to reform the Polish health system has been recognised for many years. In 1981-82 a primary health care development project was instituted, with little effect. In the late 1980s round table discussions between Solidarity and the government considered a range of proposals, but the two sides failed to reach agreement. The longstanding inability to find a solution has fuelled widespread frustration and persuaded many people that a rapid, radical change is needed.

The government has reached agreement about the desirable long term goals but is much less clear about the details. A National Health Programme was agreed in June 1990. This proposes 14 targets for the reduction of major health problems and risk factors, and is based on the WHO Health for All programme.

In the short term, many of the problems in the health sector are only too apparent. Solutions to some of them, such as the lack of drugs and investment in buildings, can only come about as part of a general economic upturn. However two areas of reform, the organisational structure and the system of financing, are potentially amenable to more rapid change.

The organisation of the system is clearly inadequate, and the numerous isolated fragments must be integrated. The Voivodeships and the ZoZs are much too small to provide a complete range of services on their own. It is likely that attempts will be made to integrate the ZoZs horizontally and to merge the 49 Voivodeships into 15 Voivodeship consortia, each of which would provide a comprehensive range of services. The parallel systems serving particular occupational groups will then be brought under the control of the Ministry of Health.

It has been more difficult to reach a consensus on a new method of health care financing, and this has provoked intensive ideological debate. ${ }^{13}$ Disillusionment with the old system led to a complete rejection of centralised control. Consequently the initial proposals from Solidarity were for a system of local health insurance schemes operating in an ill defined internal market. This suggestion was criticised as being even more fragmented than the existing system, as well as being unworkable, and a national social insurance scheme was advocated. This would attempt to redress existing geographical inequalities. An alternative suggestion from the Polish Medical Association envisages an internal market in which general practitioners would be budget holders and would purchase services from a range of state and private facilities. The government now recognises that it will be impossible to bring about a major change in the current financial situation. While a social insurance scheme will be introduced when the economy has recovered, the health service will continue to be paid for out of general government revenue for the next few years. The major change in the short term will be the introduction of either copayment or full cost recovery for certain services. Some growth in official private practice is beginning to occur, but it is likely to remain limited to acute outpatient care in a few urban centres.

THE CZECH AND SLOVAK FEDERAL REPUBLIC Health care is organised at the level of the individual republics, with two separate health 
ministries. In 1990 a working group, which included the present health minister, set out a series of options for change in the Czech Republic. ${ }^{14}$ The Slovak Republic is proceeding along similar lines. Although the exact shape of the new health systems is still being discussed, both will be financed from social insurance funds. The Czech proposals set out two principal options. In one, health associations would be established on a geographical basis to provide health services. The other envisages communities contracting with autonomous health care facilities and doctors.

\section{HUNGARY}

Recognition of the need for change surfaced under communism. A national programme of health promotion was produced in 1987. However the programme was introduced in a ministerial decree, without consultation and was independent of other areas of social policy. It is widely seen to have been a failure. ${ }^{15}$ Several proposals for a new system of financing were also examined by a reform office established by the former government, but no changes resulted from them.

The government has set out a number of goals for the new health system. As elsewhere, disillusionment with the former centrally planned system has led many to conclude that a market based solution is necessary. The Hungarian proposals for reform are the most radical of any of the central European countries, and envisage a dramatic reduction in the role of the state in both financing and delivering health care. This will be brought about through the introduction of an insurance based system with greater private provision. Resources are to be used more efficiently, with a new system of hospital reimbursement based on improved productivity and management. There will be a shift to integrated primary care as the basis for most health care delivery and improved consumer choice.

Documents relating to the proposed reforms lack detail and some contain apparent paradoxes, beginning with a commitment to reducing inequalities and providing health care as a basic right and then discussing the role of economic incentives in making people more aware of the cost of treatment. It is likely that there will be competition among purchasers and providers, with a variety of types of ownership of hospitals, and a mixture of profit-making and non-profitmaking insurance funds.

\section{BULGARIA}

In recent years there has been widespread disillusionment with the Bulgarian health system, even among government ministers. Prior to the June elections, a national coordinating council was established to discuss the future shape of the health service. The council consisted of representatives of the health ministry, medical professionals, trade unions, and the prodemocracy opposition.

The health service reforms under consideration envisage a move to a health insurance fund. ${ }^{16}$ There will be increased patient choice and competition. The governing party has rejected widespread privatisation, and it has been argued that this opposition, despite the widespread discontent with the existing system, was a factor in their electoral success. However there was clearly a multiplicity of factors involved in the election result including perceived foreign support for the opposition and racial issues involving the large Turkish minority.

The opposition party, of which the president is a member, agrees with the general direction of the reforms, but favours a greater degree of privatisation and more rapid progress. The medical profession also favours greater privatisation.

The major problem facing Bulgaria in the future is the state of the economy. The country has virtually no foreign exchange, and it is in the unfortunate position of being owed large sums of money by Iraq.

\section{ROMANIA}

The problems faced by Romania are of a different order of magnitude to its neighbours. As a result of the policies of the Ceausescu regime, Romania faces some of the worst health problems in Europe. Life expectancy at birth in Romania is five years lower than in Western Europe, and infant mortality is three times higher and rising. There are high levels of many infectious diseases including tuberculosis and severe shortages of all types of drugs and equipment. Demographic policies, inadequate food and housing, and virtually non-existent social services have left up to 150000 children in institutions which are often unable to provide even basic care. Health care staff have been isolated from developments in other countries for over 10 years.

The direction of health service reform is still under discussion, but is likely to include a mixed public and private health care delivery system and either a public or a mixed public/private insurance system. The most immediate needs of Romania continue to be international emergency aid. This is mainly being provided by nongovernmental organisations, and although there is a possibility of a World Bank loan, other forms of governmental aid will be conditional on demonstration of a greater commitment to economic reform.

\section{GERMANY}

The ultimate shape of the health system in the former DDR is much clearer than in other central European countries, and the financial strength of the western Landers will ensure that the transition is much less painful than elsewhere. As with many other aspects of life in the DDR it was inevitable that the health system would become integrated with that of the west. The inevitability of change was underlined by the collapse of many parts of the system prior to unification.

A timetable for the transition of all elements of health and social security has been set out in detail. ${ }^{17}$ The most rapid changes affect the financing of the system. Health insurance funds have already been established. Their income is derived from contributions representing $12 \cdot 8^{\circ}{ }_{0}$ of salaries. However as salaries in the east remain much lower than in the west the income of the funds is also correspondingly lower. 
The structure of the health care system will take longer to change. The organisation of ambulatory care is perhaps the major difference between the two systems. In the west, outpatient specialist care is provided by doctors who usually practise alone. In the east it is much more institutionalised and is provided in large polyclinics employing several hundred people or, especially in rural areas, smaller ambulatory care centres. The eastern system is seen by many in the west as having considerable advantages. Although the unity treaty envisages that polyclinics and ambulatory care centres should continue until the end of 1995, the Federal Government is withdrawing funding in 1991. It was envisaged that many eastern doctors would form group practices and buy the facilites, continuing to run them privately. The eastern Lander would then have assumed responsibility for the rest. Except in a few cases neither of these have happened. Several possible solutions have since been proposed, including financial aid from the western Medical Union and cooperation between the ambulatory facilities. However the future remains uncertain. ${ }^{18}$

\section{YUGOSLAVIA}

Yugoslavia, as an entity, has virtually ceased to exist. Slovenia is effectively independent and Macedonia seems likely to follow. It is impossible to know how the remaining republics will emerge from the current civil war. The existing health system differs from those elsewhere in central Europe. It was decentralised in the 1960s with financing and management of services devolved to individual communes. ${ }^{19}$ As in other central European countries there was very little coordination between neighbouring facilities, leading to duplication and gaps in services. The system has been unable to cope with the complex billing required and many secondary and tertiary care centres have run out of money. These problems have been compounded by a virtually bankrupt economy in recent years, and, even before the present unrest, the system was close to collapse. Some change is inevitable, but its nature is as yet unclear. The newly established Croatian Ministry of Health and Social Affairs proposes a health insurance fund managed at the level of the republic. Copayments will be introduced with protection for families with low incomes and others. The fragmented primary health care system will be integrated. The situation in the other republics is unclear, and the only certainty is that the new systems are likely to be different in each of them

\section{The future}

The first task in each country is to restructure the industrial base and regenerate the economy. Until that is done each country can only hope to spend about $\$ 100$ per person per year on health. However all of the health services need large sums of money to overcome the consequences of previous government policies. The most immediate requirements are for new equipment and drugs, although money will also be required to tackle the crumbling infrastructure and the low wages in the health sector. These immediate needs, however, should not be seen as an excuse for lax budgetary management in the long term. As resources will be scarce for the foreseeable future it is essential that they are used as effectively as possible.

While economic expansion will make more money available for health care, discontent with the existing organisations has compelled politicians to examine more radical approaches. Health insurance systems are attractive because of the intense distrust of state control. As a further measure, several countries, such as Poland and the Czech Republic, are attempting to make explicit what services will and will not be provided, and almost all are planning a substantial expansion of copayment. There appears to be little political opposition to this, partly because of the widespread association in many peoples' minds of free care with substandard care. However it would be unfortunate if reforms abolished the universal coverage that was one of the few strengths of the old systems.

The organisation of services will also change. There must be much greater integration of services. This will involve bringing together the disparate elements of primary health care into a single service, increasing coordination between neighbouring districts and regions, and bringing parallel systems under health ministry control. In due course there will be a need to redress the maldistribution of facilities, and in particular to strengthen health services in rural areas. This will involve substantial management skills and some painful decisions when the overprovision of secondary services, especially in cities, is rationalised. Unfortunately the record of Western European countries in this field is far from encouraging.

The West can play an important role in training. There is a virtual absence of the expertise required to manage insurance funds and health care facilities. There is also a need to restructure medical training, with much greater emphasis on primary care, and to develop skills in health service evaluation. A number of western European organisations are already active in this field, and contacts are expanding rapidly. However for training to be relevant, people in western Europe will have to acquire a much clearer understanding of the problems involved, including their cultural and historical context. This could be built up through long term links, although it is disappointing that the level of funding for the UK Academic Links projects is not greater, especially in view of the relatively high cost of postgraduate study in the UK. Links could also be used to support collaborative research, especially in view of the lack of accurate descriptive studies throughout the region. Unfortunately this is further complicated by the separation of training, in universities, and research, in ministries and academies of science, and several countries are also examining ways of restructuring their higher education systems. ${ }^{20}$

The problems faced by health care reformers in central and eastern Europe are formidable but, while they recognise their problems, they have a deep commitment to bring about improvements If they receive appropriate support they will probably succeed. 
I am grateful to many colleagues within the countries concerned, at the European Regional Office of WHO, and at the London School of Hygiene and Tropical Medicine. The views expressed are mine alone.

1 Foster DP, Jozan P. Health in Eastern Europe. Lancet 1990 335: 458-60.

2 Orosz E. The Hungarian country profile: inequalities in health and health care in Hungary. Soc Sci Med 1990; 31: 847-57.

3 Duch D, Sokolowska M. Health inequalities in Poland. Soc Sci Med 1990; 31: 343-50.

4 Anon. Clearing up after communism. The Economist 1990 17 Feb: $62-4$.

5 Johns A. Poland: Drug abuse in Eastern Europe. Lancet 1991; 337: 38-9.

Kozakiewicz M. Poland. Locked in battle with the Catholic Church. People 1989; 16: 13-5.

7 Csazi L. Interpreting inequalities in the Hungarian health system. Soc Sci Med 1990; 31: 275-84.

Searle D, Power M. Legacy of decay. Health Services 71990 100: $849-50$.

9 Forgacs I, Simon-Kiss G. Hungary: the quest for health for all. In: Tarimo E, Creese A, eds. Achieving health for all by the year 2000. Geneva; World Health Organization, 1990.

10 Minev D, Dermendjieva B, Mileva N. The Bulgarian country profile: the dynamics of some inequalities in health Soc Sci Med 1990; 31: 837-46.
11 Rich V. Czechoslovakia: the case of the missing minister. Lancet 1991; 337: 168 .

12 Tuffs A Germany: A bitter pill for the drug companies. Lancet 1991; 337: $103-4$.

13 Sheldon T. Only the fittest survive. Health Services $f 1990$ 100: $1070-1$

14 Working Group for the reform. Reform of health care in the Czech republic. Prague: Ministry of Health and Socia Affairs, 1990.

15 Makkara P. Dilemmas of health promotion and poltical changes in Eastern Europe. Health Promotion Int 1991; 6 : 41-7.

16 Bulgarian Health Ministry. Health insurance system in the Republic of Bulgaria: basic configuration. Sofia: Bulgarian Ministry of Health, 1991.

17 Der Bundesminister fur Arbeit und Sozialordnung. Bonn: Soziale Sicherheit, 1990.

18 Tuffs A. Germany: one country, two health systems. Lancet 1990; 336: 1570-1.

19 Eterovic I. Yugoslav experience of health system decentralisation. In Mills A, Vaughan JP, Smith DL, Tabibzadeh I, eds. Health system decentralization. Geneva: WHO, 1990.

20 Schweitzer J. Transition in Eastern Europe-the socia dimension. Finance and Development 1990; 27: 6-8.

FURTHER READING

Glenny M. The rebirth of history. Harmondsworth: Penguin Books, 1990

Sword K, ed. The Times guide to Eastern Europe. London: Times Books, 1990. 